\title{
Single Track of Selective Laser Melting Process: Modeling and Experimental Comparison
}

\author{
Chung-Wei Cheng ${ }^{*}$, Yao-Wen Liou ${ }^{1}$, An-Chen Lee ${ }^{1}$ and Mi-Ching Tsai \\ ${ }^{1}$ Department of Mechanical Engineering, National Chiao Tung University, No. 1001, Ta Hsueh Road, Hsinchu 300, Taiwan \\ ${ }^{2}$ Department of Mechanical Engineering, National Cheng Kung University, Tainan, Taiwan \\ E-mail: weicheng@nctu.edu.tw
}

\begin{abstract}
This study uses finite element software to simulate the single melted track of powder (Maraging Steel) on a substrate (S45C). The simulation model considers the absorption penetrating depth of laser power on the powder bed and the penetrating energy irradiating the substrate. A volumetric heat source is applied to the powder bed model, and a surface heat source is applied to the substrate model to obtain the simulated temperature field distribution. The interface melt width between the powder bed, substrate surface, and the substrate melt depth are estimated according to the temperature field distribution. In the experiments, a self-developed SLM experimental system is used, and the laser power and scanning speed are adjusted to observe the effect of a single continuous track on the S45C substrate, which is compared with a theoretical simulation.
\end{abstract}

DOI: $10.2961 /$ jlmn.2019.02.0004

Keywords: selective laser melting, SLM, absorption penetrating depth, interface melt width

\section{Introduction}

Among the Additive manufacturing (AM) methods being developed at present, the selective laser melting (SLM) method involves the use of a focused laser beam for selectively melting powdered metallic material [1], and the fabricated $3 \mathrm{D}$ part is characterized as having high mechanical strength. As SLM has the ability to directly fabricate complex parts, it has received global attention.

While there have been studies using experimental designs to identify the appropriate SLM process parameters, such processes spend too much time on measurement and analysis. Childs et al. [2] used different combinations of process parameters, i.e. laser power and scanning speed, to investigate the effect of forming a structure. Yadroitsev et al. $[3,4]$ discussed the effect of the ratio of laser power to scanning speed on the formation of a single melted track, and found that the optimum single melted track had a good metallurgically bond feature with the substrate.

Some studies use simulation and experimental design to find appropriate SLM process parameters. Gusarov et al. [5] studied the melt pool temperature distribution of a single track and used the experimental cross-sectional melted track for comparison and verification. Disregarding the RayleighPlateau instability effect occurring from surface tension, the simulation model can predict the interface melt width between the single track and substrate. $\mathrm{Li}$ and $\mathrm{Gu}$ [6] used finite element software to simulate the SLM process of $\mathrm{Ti}$ powders with a surface heat source on the powder bed, and used the experimental results from the single track for verification. Foroozmehr et al. [7] used finite element software to investigate the SLM process of stainless steel $316 \mathrm{~L}$ powders. This study considers the absorption penetrating depth of laser power on the powder bed; the heat source is applied in the form of volumetric heat source. However, the penetrating laser energy irradiating the substrate is not considered.
This study uses finite element software to simulate the single melted track of the powder (Maraging Steel, MS1) on the substrate (S45C). The simulation model considers the absorption penetrating depth of laser power on the powder bed and the penetrating energy irradiating the substrate. The volumetric heat source is applied to the powder bed model, and the surface heat source is applied to the substrate model, in order to obtain the simulated temperature field distribution. The interface melt width between the powder bed, substrate, and the substrate melt depth are estimated according to the temperature field distribution. In experiments, the self-developed SLM experimental system is used, MS1 is selected as the metal powder material, and the laser power and scanning speed are adjusted to examine the effect of a single continuous track on the S45C substrate, which is compared with a theoretical simulation.

\section{Finite Element Modeling}

A single layer powder on the substrate is normally irradiated by a laser beam, as shown inFig. 1 . When the laser beam irradiates on the powder surface, the laser beam is partially reflected by the powder and partially transmitted into the internal powders and substrate surface via a multiple scattering effect. In Fig. 2(a), ANSYS software is used to build a three-dimensional finite element model to study the heat transfer during the SLM process, i.e. a single-layer powder bed (MS1) on the substrate (S45C). Considering the multiple scattering effect, a volumetric heat source is applied to the powder bed, and a surface heat source is applied to the substrate surface.

The single-layer powder bed is assumed to be a continuous and uniform medium, and a $30 \mu \mathrm{m}$ thick powder bed model is built on the substrate. Assuming that the single laser track is scanned in the middle of the powder bed in the SLM process, $1 / 2$ of the model is analyzed. The temperature field distribution of the space model (3D) is analyzed, and a 
SOLID70 element (size $10 \mu \mathrm{m}$ ) is used for definition. This element comprises 8 nodes, with each node having only one temperature degree of freedom. This study investigates the interface melt width and substrate melt depth by judging how many nodes exceed the $\mathrm{S} 45 \mathrm{C}$ melting temperature $\left(1520^{\circ} \mathrm{C}\right)$, as shown in Fig. 2(b). In terms of boundary conditions and initial conditions, only the heat transfer effect is considered, and the substrate/powder layers are preheated to $200^{\circ} \mathrm{C}$.

In the single melted track process, the laser heat source moves and irradiates along the path, and the melted track is cooled and solidified as the heat source leaves. Accordingly, the material parameters of the previously irradiated area should be updated based on the melting pool area. ANSYS finite element software judges whether the temperature values of all nodes in the melt pool generated by previous irradiation exceed the melting temperature of the selected material (e.g. $1413^{\circ} \mathrm{C}$ of $\mathrm{MS} 1$ ). When the temperature values of all nodes are higher than the melting point, the nodes change from a powder to a solid, and the program selects this unit to update the material parameters.

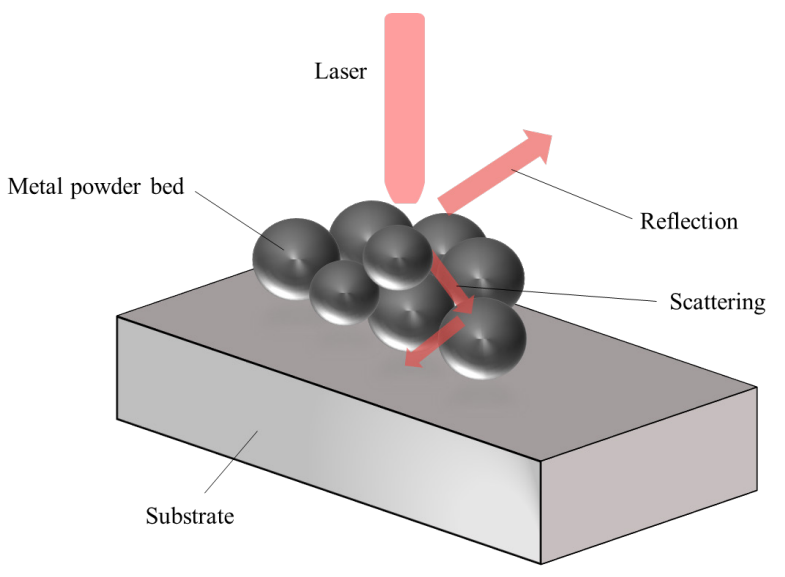

Fig. 1 Schematic for modeling

(a)

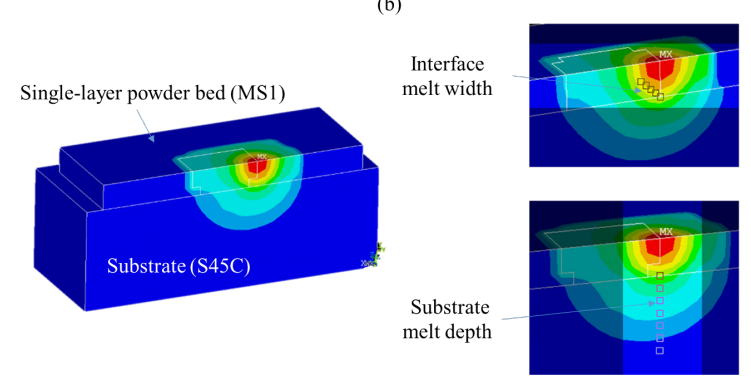

Fig. 2 (a) Finite element model and (b) interface melt width and substrate melt depth

In the material properties definition, the effective thermal conductivity of the powder bed and $1 \%$ of the thermal conductivity of the bulk material is used [8]:

$$
k_{\text {powder }}=\left\{\begin{array}{ll}
0.01 \times k_{\text {solid }} & T<T_{m} \\
k_{\text {solid }} & T \geq T_{m}
\end{array}\right\}
$$

where $k_{\text {solid }}$ and $T_{m}$ are the thermal conductivity and melting temperature of MS1 bulk material, respectively. $T$ is the powder bed temperature.

As the powder bed is formed of powder particles and protective gas, the powder bed density and volumetric heat capacity are related to porosity, and can be expressed as Eqs. (2) and (3):

$$
\begin{aligned}
\rho_{\text {powder }}=\emptyset \rho_{\text {gas }}+ & (1-\emptyset) \rho_{\text {solid }} \\
\rho_{\text {powder }} C_{\text {powder }}= & \emptyset\left(\rho_{\text {gas }} C_{\text {gas }}\right) \\
& +(1-\emptyset)\left(\rho_{\text {solid }} C_{\text {solid }}\right)
\end{aligned}
$$

where $\varnothing$ is the porosity of the powder bed, and $\rho_{\text {gas }}$ and $\rho_{\text {solid }}$ are the densities of the protective gas and metal bulk, respectively. $C_{g a s}$ and $C_{\text {solid }}$ are the specific heat capacities of the protective gas and metal bulk, respectively. When the temperature of the material approaches the melting temperature, the latent heat of fusion should be considered. This study uses MS1 $\left(\mathrm{d}_{50}=30 \mu \mathrm{m}\right)$ as the metal powder, and $\emptyset$ is calculated to be about 0.51 .

This study uses MS1 as the metal powder, and its material composition is similar to maraging steel grade 300 . Assume both material properties are similar, the $\rho_{\text {solid }}=8000 \mathrm{~kg} / \mathrm{m}^{3}, C_{\text {solid }}=452 \mathrm{~J} / \mathrm{kg} \cdot{ }^{\circ} \mathrm{C}, K_{\text {solid }}=19.6$ $\mathrm{W} / \mathrm{m} \cdot{ }^{\circ} \mathrm{C}$, and $T_{m}=1413^{\circ} \mathrm{C}$ are used. The protective gas is nitrogen, i.e. $\rho_{\text {gas }}=1.26 \mathrm{~kg} / \mathrm{m}^{3}, C_{\text {gas }}=1021.6 \mathrm{~J} / \mathrm{kg} \cdot{ }^{\circ} \mathrm{C}$. The above parameters were substituted in Eqs. (1)-(3) to obtain the thermal properties of the powder bed. The thermal properties for the substrate material (S45C) can be found in [9].

In the definition of a laser heat source, the powder can be heated uniformly and the volumetric heat source can be considered in the simulation [7]:

$$
H_{s}=\frac{(1-R) \times P}{\left(\pi \times r^{2}\right) \times \delta_{1} \times O P D}
$$

where $H_{S}$ is the volumetric heat source $\left(\mathrm{W} / \mathrm{m}^{3}\right), R$ is the surface reflectivity of the MS1 powder, $P$ is the laser power, $r$ is the radius of the laser focal spot size, $\delta_{1}$ is the experimentally corrected parameter, and $O P D$ is the optical penetration depth. In this study $R=0.64, r=20 \mu \mathrm{m}$, $\delta_{1}=0.7$ [7], and $O P D=30 \mu \mathrm{m}$.

According to the definition of the heat source applied to the substrate's surface, the surface heat source is applied. As the absorption penetration depth of S45C is about $20 \mathrm{~nm}$ [10], the penetration depth of the laser beam into the bulk is too small, thus, the heat source effect of this region is described by surface type. Assume the scattering laser light on the substrate surface is a Gaussian distribution:

$$
\begin{aligned}
I(x, y)= & \frac{(1-R)^{2} \times \delta_{2} \times P}{\pi \times r^{2}} \\
& \times e^{-2\left(\frac{\sqrt{\left(x-x_{0}\right)^{2}+\left(y-y_{0}\right)^{2}}}{r}\right)^{2}}
\end{aligned}
$$

where $\delta_{2}$ is the transmitted parameter, and $x_{0}$ and $y_{0}$ are the center of the heat source of laser radiation. In this study, $\delta_{2}=0.687$. 


\section{Experiment}

The SLM-produced MS1 single track structures on the S45C substrate were fabricated using a self-developed SLM experimental system. The SLM process took place inside the processing chamber with a protective gas atmosphere (nitrogen air flow), and a focused laser beam was used to selectively melt the powders. The powder (EOS MS1) with $\mathrm{d}_{50}=30 \mu \mathrm{m}$, was processed with a layer thickness of $30 \mu \mathrm{m}$ on the substrate by a powder feeding module.

The system had an infrared fiber laser with a laser wavelength $1070 \mathrm{~nm}$, a laser beam diameter of $5 \mathrm{~mm}$, and a maximum laser power of $200 \mathrm{~W}$. The laser beam was passed through a beam expander (magnification $2 \mathrm{x}$ ) and mirrors, and subsequently entered a galvanometric scanner with an F-theta lens (focal length $210 \mathrm{~mm}$ ). The laser beam transmitting through the F-theta lens was incident in the normal direction on the metal powder surface. The focal spot's diameter was determined to be approximately $40 \mu \mathrm{m}$.

Single melted tracks were fabricated using the processing parameters, e.g. a preheated temperature of $200^{\circ} \mathrm{C}$ on the base plate and an oxygen concentration of $<$ $3000 \mathrm{ppm}$. The characteristics of the fabricated samples were measured using Optical microscopy and Scanning electron microscopy (SEM, Hitachi SU-8010). An Energy Dispersive Spectrometer (EDS) was used to study the chemical composition of the melted zone.

\section{Results and Discussion}

\subsection{Single laser melted track}

Fig. 3 presents the surface morphology of the single laser melted tracks fabricated by a laser power of $79 \mathrm{~W}$, a scanning speed in the range of $10-150 \mathrm{~mm} / \mathrm{s}$, and a preheating temperature of $200^{\circ} \mathrm{C}$. In the scanning speed of $10-30 \mathrm{~mm} / \mathrm{s}$, it was observed that both sides of the melted track were non-uniform (marked by blue dashes). When the scanning speed was slow, the irradiated time on the powder surface was prolonged, the heat affected zone was increased, and the subsequent solidification structure had large and round morphology. The reflected light on the surface gradually became continuous as the scanning speed increased, presenting an optimum single line continuous structure.

As the scanning speed increased to a certain level, the single track turned from a continuous form into a discontinuous type. A discontinuous broken track is formed at higher scanning speeds, i.e. 140 and $150 \mathrm{~mm} / \mathrm{s}$. This can be explained by Rayleigh-Plateau instability, where a nonideal continuous body [5] or an excessive scanning speed limits the laser energy penetrating into the pervious layer. As the scanning track cannot be molten well, the radial and transverse directions of the melt track shrink excessively during solidification, and a drop-shaped broken line track is formed [11].

Fig. 4 shows the cross-sectional SEM image of single melt tracks (scanning speed $60 \mathrm{~mm} / \mathrm{s}$ and $100 \mathrm{~mm} / \mathrm{s}$ ), and the interface melt width and substrate melt depth are measured. Note that the proportional change in the $\mathrm{Ni}$ element can be obtained by an Energy Dispersive X-ray Analyzer, which is used to judge the substrate melt depth. It is found that, as the scanning speed increased, the proportional $\mathrm{Ni}$ element is decreased, e.g. from $\sim 40 \%$ to $\sim 30 \%$.

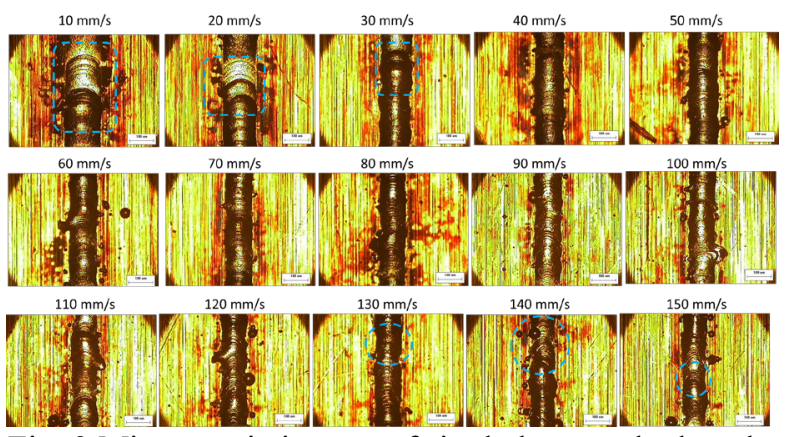

Fig. 3 Microscopic images of single laser melted tracks fabricated by different scanning speeds (scale bar $100 \mu \mathrm{m}$ )

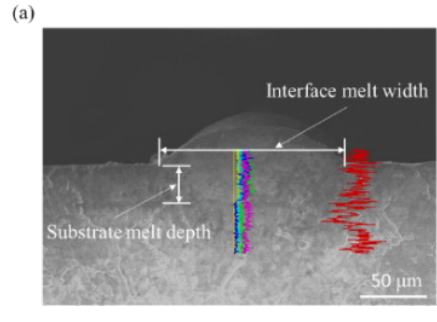

(b)
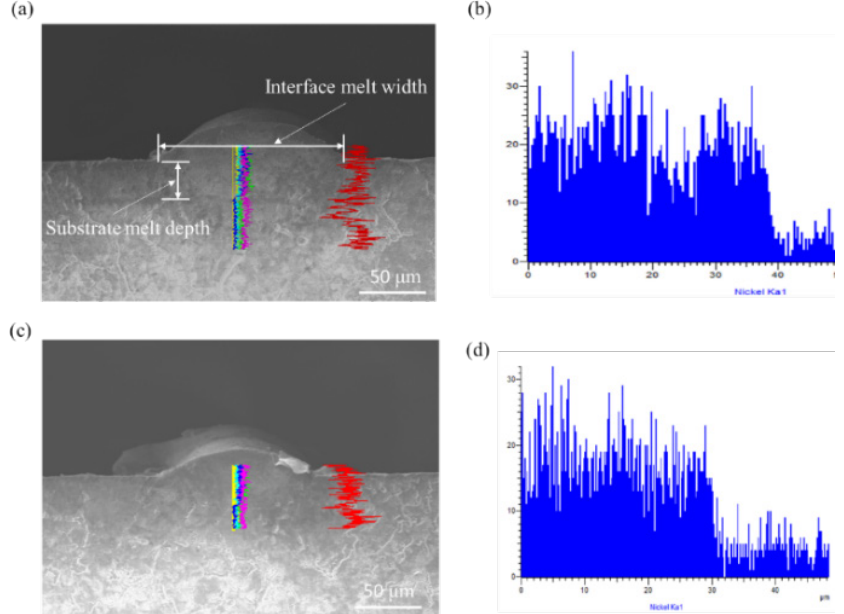

Fig. 4 Cross-sectional SEM image of singe melt tracks (a)(b) $60 \mathrm{~mm} / \mathrm{s}$ (c)(d) $100 \mathrm{~mm} / \mathrm{s}$

\subsection{Comparison of simulation and experimental results}

Fig. 5 shows the comparison between the simulated and experimental interface melt depths. The simulation results that only consider the volumetric heat source are lower than the simulation results after applying a volumetric heat source and surface heat source. The data from the simulation (volumetric heat source and surface heat source) are approximate, as compared to the experimental measurement, and their trends are consistent with the average percentage error of $14.3 \%$, which is smaller than the average percentage error of $39.2 \%$ by the simulation (volumetric heat source) result. The minimum error is about $6 \%$ at scanning speed $60 \mathrm{~mm} / \mathrm{s}$. 


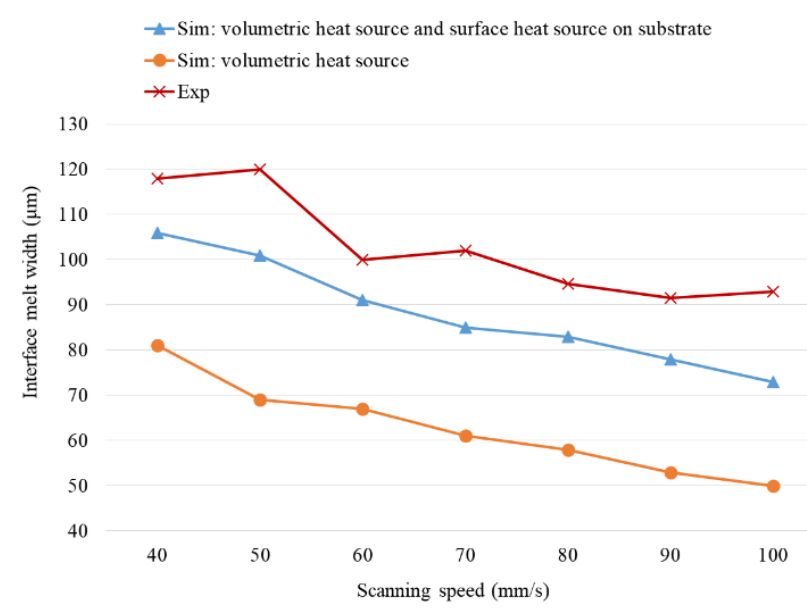

Fig. 5 Simulated and experimental interface melt width

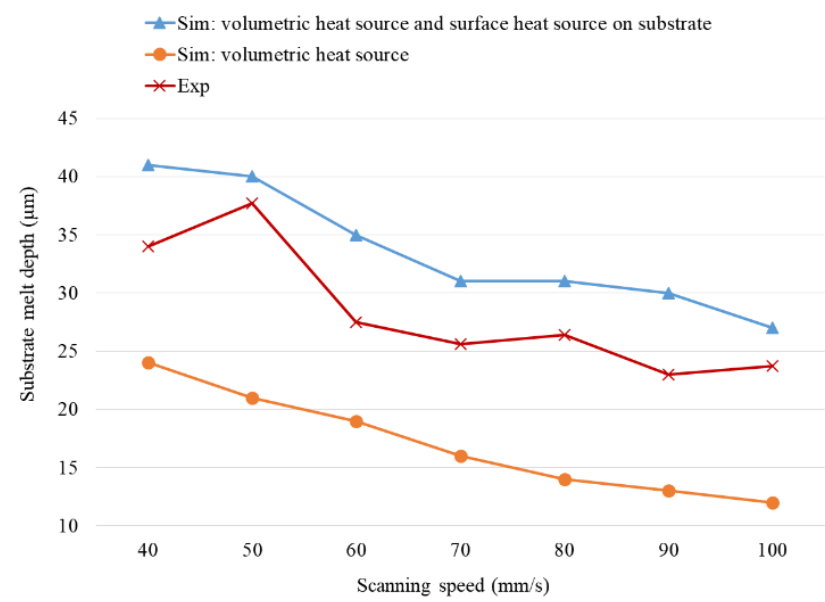

Fig. 6 Simulated and experimental substrate melt depth

Fig. 6 shows the experimental measurements, simulation (volumetric heat source and surface heat source), and simulation (volumetric heat source) data of the substrate melt depth. It is found that the simulation data after applying two heat sources are higher than the simulation results only considering the volumetric heat source. As the surface heat source on the substrate is not considered, the heating of the substrate cannot continue to heat the material, thus, the melt depth of the substrate cannot be continuously increased.

The data from the simulation (volumetric heat source and surface heat source) are approximate, as compared to the experimental measurement, and their trends are consistent with the average percentage error of $19.5 \%$, which is smaller than the average percentage error of $40.3 \%$ by the simulation (volumetric heat source) result. The minimum error is about $9 \%$ at scanning speed $50 \mathrm{~mm} / \mathrm{s}$. The differences resulting from the actual single track and substrate material have a mixing interface region, which influences the actual heat transfer in this region; however, this simulation disregards the heat transfer problem in this mixing region. The heat is transferred continuously and directly by the preset substrate heat transfer of the model. Finally, the substrate melt depth is judged by the temperature field of the substrate model to be higher than the material melting point, as compared with the experimental measurements.

\section{Conclusion}

This study uses finite element software to analyze the SLM process. Different heat sources are applied to the finite element model, e.g. a volumetric heat source is applied to the powder bed, and a surface heat source is applied to the substrate surface. The results of simulation (volumetric heat source and surface heat source) are more accurate than simulations that only consider the volumetric heat source. The average percentage error between the interface melt width of the simulation (volumetric heat source and surface heat source) data and experimental measurements is $14.3 \%$. In terms of the substrate melt depth, the heat transfer problem in the actual material mixing zone is disregarded; the average percentage error between the simulation (volumetric heat source and surface heat source) data and experimental measurements is $19.5 \%$.

\section{Acknowledgements}

The authors gratefully acknowledge the support of the Ministry of Science and Technology for this research under grants MOST 106-3114-E-006-011 and MOST 105-2221E-009 -064 -MY3.

\section{References}

[1] F. Abe, K. Osakada, M. Shiomi, K. Uematsu, and M. Matsumoto: J. Mater. Process. Technol., 111, (2001) 210.

[2] T.H.C. Childs, C. Hauser, and M. Badrossamay: CIRP Ann. Manuf. Technol., 53, (2004) 191.

[3] I. Yadroitsev, P. Bertrand, and I. Smurov: Appl. Surf. Sci., 253, (2007) 8064.

[4] I. Yadroitsev, A. Gusarov, I. Yadroitsava, and I. Smurov: J. Mater. Process. Technol., 210, (2010) 1624.

[5] A.V. Gusarov, I. Yadroitsev, P. Bertrand, and I. Smurov: Appl. Surf. Sci., 254, (2007) 975.

[6] Y. Li and D. Gu: Addit. Manuf., 1-4, (2014) 99.

[7] A. Foroozmehr, M. Badrossamay, E. Foroozmehr, and S.i. Golabi: Mater. Des., 89, (2016) 255.

[8] T. Craeghs, S. Clijsters, E. Yasa, F. Bechmann, S. Berumen, and J.-P. Kruth: Opt. Lasers. Eng., 49, (2011) 1440.

[9] D. Deng, Y. Luo, H. Serizawa, M. Shibahara, and H. Murakawa: TRANS JWRI, 32, (2003) 325.

[10] T.Y. Hwang, A.Y. Vorobyev, and C. Guo: Appl. Phys. Lett., 95, (2009) 123111.

[11] D. Gu and Y. Shen: J. Alloys Compd., 432, (2007) 163166.

(Received: June 7, 2018, Accepted: June 16, 2019) 